\title{
Growth mechanism of N-doped graphene materials and their catalytic behavior in the selective oxidation of ethylbenzene
}

\author{
Pei Tang, Yongjun Gao, Jinghe Yang, Wenjing Li, Huabo Zhao, Ding Ma* \\ Beijing National Laboratory for Molecular Sciences, College of Chemistry and Molecular Engineering, Peking University, Beijing 100871, China
}

\section{A R T I C L E I N F O}

Article history:

Received 15 May 2014

Accepted 21 May 2014

Published 20 June 2014

\section{Keywords:}

$\mathrm{N}$-doped graphene

Heteroatom

Growth mechanism

Oxidation of ethylbenzene

\begin{abstract}
A B S T R A C T
$\mathrm{N}$-doped graphene materials were prepared from both inorganic and organic nitrogen sources and pyrolytic graphene oxide as the carbon substrate. Transmission electron microscopy, scanning electron microscopy, Raman spectroscopy, and X-ray photoelectron spectroscopy were used to investigate the detailed growth mechanism of the $\mathrm{N}$ species in these $\mathrm{N}$-doped graphene materials. The different chemical nature and binding energy of the different $\mathrm{N}$ species resulted in their different trends with annealing temperature. These $\mathrm{N}$-doped graphene are excellent catalysts in the oxidation of ethylbenzene. A high yield of acetonphenone did not depend on the total nitrogen amount but only on the type of nitrogen species. Too much defects and N-dopants were detrimental to this reaction. A proper activation of the oxidant is needed to get good catalytic activity.
\end{abstract}

(C) 2014, Dalian Institute of Chemical Physics, Chinese Academy of Sciences. Published by Elsevier B.V. All rights reserved.

\section{Introduction}

Carbon materials, like activated carbon, carbon black, and carbon molecular sieves, have been successfully employed as supports in heterogeneous catalysis [1]. Besides these traditional carbon materials, many nano-carbon materials like carbon nanofibres, carbon nanotubes [2], and graphene [3,4] are also excellent catalyst supports. In recent years, these widely accessible and inexpensive carbon materials have also been utilized as catalysts, and this field known as carbocatalysis has become a hot topic $[5,6]$. Their tunable surface functional groups, unique conjugated structures, environmental friendly nature, and easy reusability make them good replacements for the traditional metal and metal oxide catalyst systems $[7,8]$.

A wide range of meaningful and interesting carbocatalytic reactions have been found, which include oxidative dehydrogenation reaction of ethylbezene [9] and $n$-butane [10] and the selective oxidation of cyclohexane [11] and benzyl alcohol [12].
Our group also discovered that graphene-based nano-carbon materials can catalyze the reduction of nitrobenzene $[13,14]$ and selective oxidation of ethylbenzene [15] and benzene [16]. In these carbocatalysis systems, it was observed that doping with heteroatoms can improve the catalytic activity of the carbon materials. For example, doping with $\mathrm{P}$ can heal the defects in the CNTs and suppress the side reactions in the oxidative dehydrogenation reaction [17]. Dopants of nitrogen have been shown to promote the adsorption of nitrobenzene to change the reaction kinetics [18]. We also proposed that graphitic nitrogen species can activate their neighboring carbon atoms to facilitate the adsorption and activation of oxidants [15]. B dopants, with strong electron withdrawing ability, significantly improved the catalytic activity of graphene sheets in oxygen reduction reaction in alkaline electrolytes [19]. Besides these common dopants (N, P, B), Si, S, and Se dopants are also good promoters in the catalysis by carbon materials [20]. The oxidation groups and conjugated electrons of the carbon structure

\footnotetext{
* Corresponding author. Tel/Fax: +86-10-62758603; E-mail: dma@pku.edu.cn

This work was supported by the National Natural Science Foundation of China $(21176221,21273224)$ and the National Basic Research Program of China (973 Program, 2011CB201402, 2013CB933100).

DOI: 10.1016/S1872-2067(14)60150-9 | http://www.sciencedirect.com/science/journal/18722067 | Chin. J. Catal., Vol. 35, No. 6, June 2014
} 
are very important in these carbocatalysis systems [9,10,21].

Although the promoting effect of heteroatoms in carbocatalysis systems is widely accepted, there are few papers on the growth mechanism of the doped carbon materials, and papers about the control of the chemical nature of the dopant and their corresponding catalytic activity are even less. In this paper, we report that the amount and composition of dopant in $\mathrm{N}$-doped graphene can be adjusted by tuning the precursor and annealing temperature. Characterization by transmission electron microscopy (TEM), scanning electron microscopy (SEM), Raman spectroscopy, and X-ray photoelectron spectroscopy (XPS) showed different nitrogen species to show a distinct changing trend with annealing temperature and different optimum temperature for doping graphene sheets. These $\mathrm{N}$-doped graphene materials are good catalysts in the selective oxidation of ethylbenzene and the composition of the $\mathrm{N}$ dopants and defects are argued to be responsible for their catalytic activity. Furthermore, too much active graphitic nitrogen and defects play a detrimental role in the reaction. This paper could pave the way to understand the growth mechanism of dopants in carbon materials and help in the design of more active carbocatalysts.

\section{Experimental}

\subsection{Materials}

Graphite (99.9\%) was purchased from LiuMao Graphite Mining Company. All the other chemicals were commercially available in at least analytical reagent grade and were used without further purification. Acetonitrile and aqueous ammonia (25\%) were purchased from Beijing Chemicals Works.

\subsection{Preparation of $\mathrm{N}$-doped graphene}

Graphene oxide was prepared by the modified Hummers' methods previously reported $[5,15]$. $\mathrm{HCl}$ water solution $(5 \%)$ was used to remove residual Mn elements. After the graphene oxide powder was dried in a $60^{\circ} \mathrm{C}$ oven for more than $24 \mathrm{~h}$, the powder was heated to $250{ }^{\circ} \mathrm{C}$ at $20{ }^{\circ} \mathrm{C} / \mathrm{min}$. Then the powder was pyrolyzed to pyrolytic graphene oxide (PGO). These PGO materials were used as the carbon precursor and acetonitrile or aqueous ammonia was used as the nitrogen precursor respectively. $\mathrm{N}_{2}$ (>99.999\%) was used as the carrier gas to feed the saturated vapor of acetonitrile or aqueous ammonia to the PGO (shown in Scheme 1). For the annealing experiment, 50

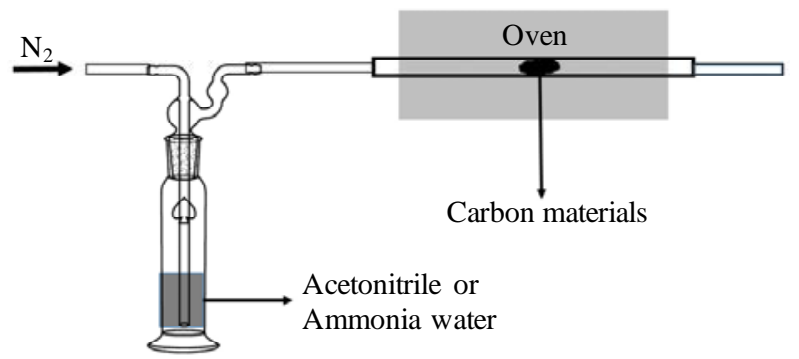

Scheme 1. Preparation of N-doped graphene. mg PGO was packed into a quartz tube and the oven was heated to $250,450,650$, or $850{ }^{\circ} \mathrm{C}$ and maintained for $6 \mathrm{~h}$. These $\mathrm{N}$-doped graphene materials were labelled as Ac- $T$ and Am- $T$ (Ac and Am for acetonitrile and aqueous ammonia, respectively, and $T$ indicated the annealing temperature). For example, Ac-850 means the samples was prepared from PGO and acetonitrile at $850{ }^{\circ} \mathrm{C}$. The weight of PGO before and after the treatment was recorded.

\subsection{Catalytic reaction of oxidation of ethylbenzene}

For the oxidation of ethylbenzene, $10 \mathrm{mg}$ catalyst, $1 \mathrm{mmol}$ ethylbenzene, $3 \mathrm{mmol}$ tert-butyl hydroperoxide (TBHP), and 3 $\mathrm{mL} \mathrm{H}_{2} \mathrm{O}$ were put into a $50 \mathrm{~mL}$ sealed pressure glass vessel with magnetic stirring. After reaction at $80{ }^{\circ} \mathrm{C}$ for $24 \mathrm{~h}, 0.05 \mathrm{~g}$ dodecane and $6 \mathrm{~mL} \mathrm{CH}_{2} \mathrm{Cl}_{2}$ were added into the tube as internal standard and extraction liquid, respectively. Upon removal of the catalyst, the mixture was analyzed by an Agilent GC 7820A equipped with a HP-5 column and an FID detector.

\subsection{Decomposition of TBHP}

The decomposition ratio of TBHP in the different catalysts was determined by the gasometric method given in our previous paper [22]. For each experiment, $30 \mathrm{mg}$ catalyst, $30 \mathrm{mmol}$ TBHP, and $30 \mathrm{~mL} \mathrm{H}_{2} \mathrm{O}$ were used with magnetic stirring.

\subsection{Characterization}

TEM images were obtained with a Tecnai G220 S-Twin microscope operating at an accelerating voltage of $200 \mathrm{kV}$. SEM images were collected with a KYKY-AMRAY-1000B microscope. Raman measurements were performed under ambient conditions using a $532 \mathrm{~nm}(2.33 \mathrm{eV})$ laser in the back-scattering configuration on a Jobin-Yvon HR800 spectrometer. XPS spectra were obtained using an Axis Ultra spectrometer (Kratos, UK). A monochromatic Al- $K_{\alpha}(1486.6 \mathrm{eV}) \mathrm{X}$-ray source was used at a power of $225 \mathrm{~W}(15 \mathrm{kV}, 15 \mathrm{~mA})$. To compensate for surface charging effects, the binding energies were calibrated using the $\mathrm{C} 1 s$ carbon peak at $284.8 \mathrm{eV}$.

\section{Results and discussion}

\subsection{Growth mechanism of the $\mathrm{N}$ species in the $\mathrm{N}$-doped graphene}

The morphology of these N-PGO materials was analyzed by TEM, SEM, and their mass change before and after the doping process. The mass changes of these PGO materials are listed in Table 1 . For the acetonitrile treated samples at $250{ }^{\circ} \mathrm{C}$, where the decomposition ratio of acetonitrile was low, the weight loss resulted from the removal of oxygen groups, while at higher temperatures $\left(450-850^{\circ} \mathrm{C}\right)$, their weight increases and particularly, at $850{ }^{\circ} \mathrm{C}$, the weight increased several fold. At high temperatures, the decomposition ratio of acetonitrile increased much, which resulted in much carbon deposition and weight gain processes. The PGO materials treated with aqueous am- 
Table 1

Mass change of PGO after the doping process.

\begin{tabular}{lcc}
\hline \multirow{2}{*}{ Temperature $\left({ }^{\circ} \mathrm{C}\right)$} & \multicolumn{2}{c}{ Nitrogen resource (\%) } \\
\cline { 2 - 3 } & Acetonitrile & Ammonia water \\
\hline 250 & -14 & -5.3 \\
450 & 0.30 & -8.2 \\
650 & 20 & -22 \\
850 & 330 & -82 \\
\hline
\end{tabular}

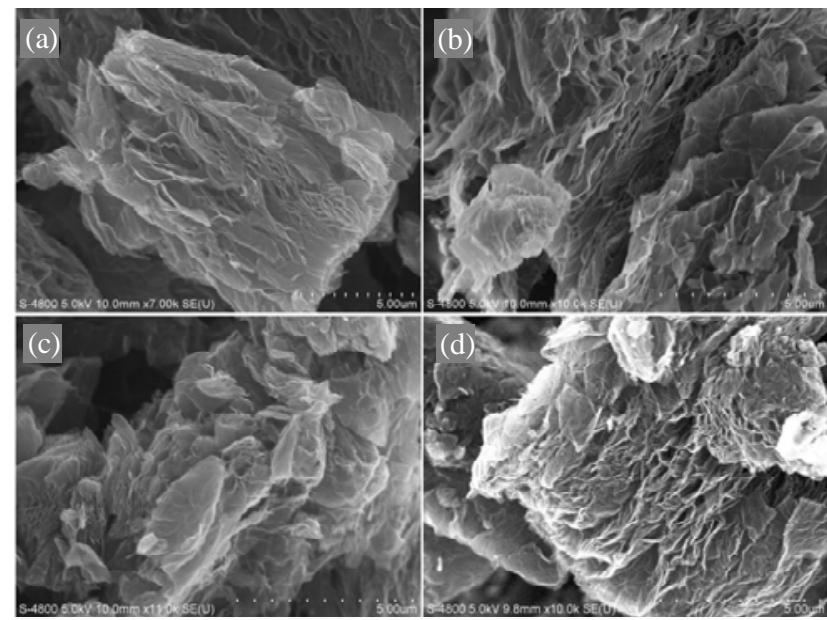

Fig. 1. SEM images of (a) PGO, (b,c) Ac-850, and (d) Am-850.

monia show increasing amounts of weight loss with annealing temperatures. Two reasons can explain this phenomenon: the removal of oxygen groups in the inert atmosphere and the carbon atom is oxidized by steam at high temperatures. SEM images of the PGO materials before and after the N-doping treatment are shown in Fig. 1. The PGO materials (Fig. 1(a)) are formed by separated graphene sheets because of the delamination of graphite oxide in the pyrolytic process. After the doping process, their layered structure remained indicating the uniformity of the $\mathrm{N}$-doping and carbon deposition processes. Moreover, the TEM images of the Am-850 and Ac-850 materials (Fig. 2) showed that the PGO materials after the treatment with acetonitrile have gone through a heavy carbon deposition process. These TEM images are consistent with the weight changes shown in Table 1. It is clear that all the materials shown were typical layered shapes of graphene, which means that the annealing treatment did not change the original structure of the PGO.

Raman spectroscopy was also used to further understand

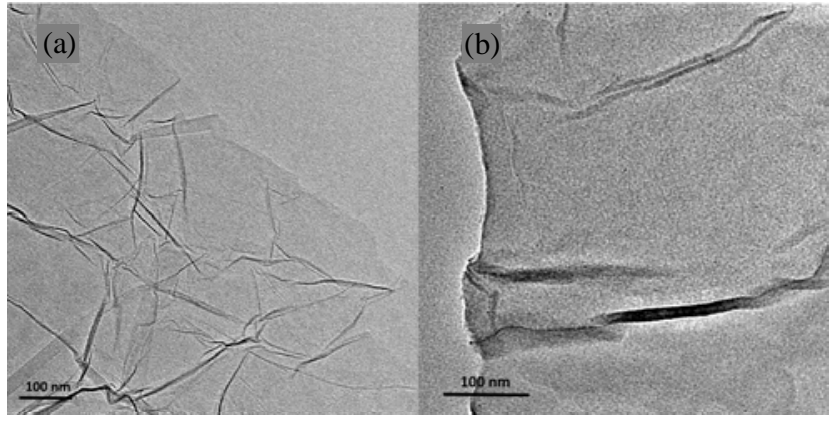

Fig. 2. TEM images of (a) Am-850 and (b) Ac-850.

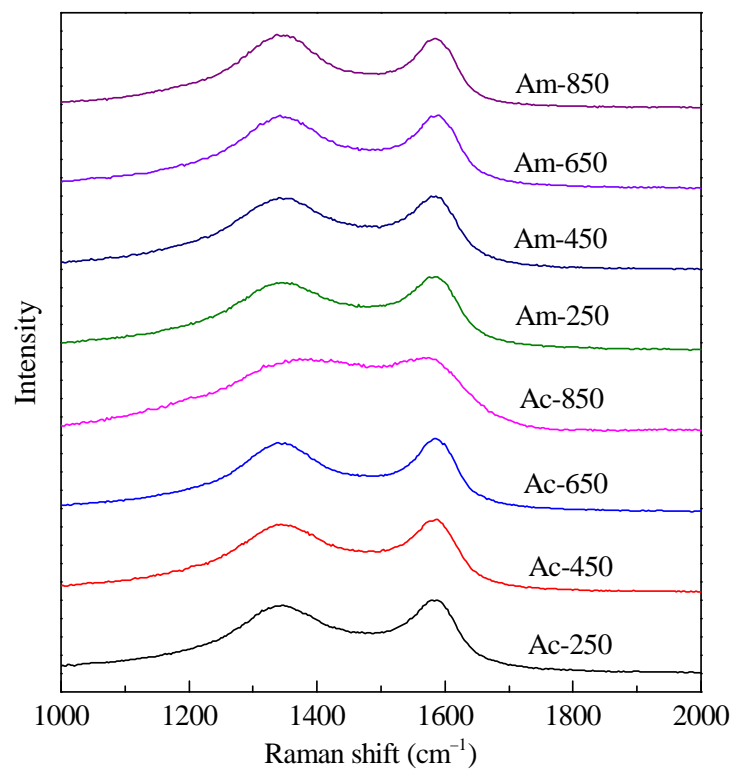

Fig. 3. Raman spectra of the N-doped graphene materials.

the doping process. All these carbon materials showed an obvious D band at $1350 \mathrm{~cm}^{-1}$ and a $G$ band at $1580 \mathrm{~cm}^{-1}$ [15] in Fig. 3. For the aqueous ammonia treated samples, the $I_{\mathrm{D}} / I_{\mathrm{G}}$ ratio increased with annealing temperatures because of more corrosion action of steam at higher temperatures. Of these $\mathrm{N}$-doped graphene materials, the Ac-850 sample had the largest $I_{\mathrm{D}} / I_{\mathrm{G}}$ ratio indicating that this sample has more defects than the other samples. Because of carbon deposition, the N-doped graphene with acetonitrile as nitrogen source showed a gradual overlap of the D and G bands [23]. This overlap was obvious for the Ac-850 sample as the most carbon deposition occurred at $850{ }^{\circ} \mathrm{C}$. The changing trends of the Raman spectra agreed with the weight change data in Table 1 and the TEM images. Furthermore, at the same treatment temperature, the aqueous ammonia treated samples showed a higher $I_{\mathrm{D}} / I_{\mathrm{G}}$ ratio than the acetonitrile treated ones because more oxygen remained in these examples.

The XPS spectra provided more information on the growth mechanism of these $\mathrm{N}$-doped graphene materials. The $\mathrm{O}$ and $\mathrm{N}$ contents from XPS are listed in Table 2. First, the XPS results showed that the $\mathrm{N}$ content of all these materials increased with annealing temperatures except for the Ac-650 sample. A general trend that the 0 content decreased with the doping of $\mathrm{N}$ occurred. The loss of $\mathrm{O}$ was partially due to the reductive sub-

Table 2

$\mathrm{O}$ content and $\mathrm{N}$ content of the $\mathrm{N}$-doped samples determined by XPS.

\begin{tabular}{lcc}
\hline Sample & O content & N content \\
\hline Ac-250 & 11 & 0.59 \\
Ac-450 & 7.9 & 4.8 \\
Ac-650 & 4.4 & 3.8 \\
Ac-850 & 3.0 & 6.1 \\
Am-250 & 9.5 & 2.0 \\
Am-450 & 7.9 & 2.6 \\
Am-650 & 3.9 & 4.6 \\
Am-850 & 4.6 & 5.2 \\
\hline
\end{tabular}


stitution by $\mathrm{N}$ in the doping process [24]. Besides, a high temperature treatment under an inert atmosphere also improved the crystallinity of the PGO and derived O [25]. Am-850 has a higher 0 content than Am-650 due to the strong steam corrosion at a higher temperature. Hence, aqueous ammonia in this annealing process not only decreased the oxygen amount of the PGO (effect of ammonia gas) but also corroded carbon atoms at high temperatures (effect of steam). Although the Am-850 sample did not have the highest $\mathrm{N}$ content, but because of the extraction of oxygen, it still possessed the largest $I_{\mathrm{D}} / I_{\mathrm{G}}$ ratio in the Raman spectra.

In order to further understand the growth mechanism of the $\mathrm{N}$ species in these $\mathrm{N}$-graphene materials, a deconvolution process was used to get the detailed composition of the $\mathrm{N}$ species (Fig. 4). The $\mathrm{N}$ elements were fitted into five species: pyridinic nitrogen species at $398.4 \mathrm{eV}$, amino nitrogen species at 399.3 $\mathrm{eV}$, pyrrollic nitrogen species at $400.2 \mathrm{eV}$, and the species at 401.1 and $403.5 \mathrm{eV}$ assigned to graphitic and $\mathrm{N}^{+-} \mathrm{O}^{-}$nitrogen, respectively $[15,24,26]$. At low annealing temperatures (250 and $450{ }^{\circ} \mathrm{C}$ ), most of the nitrogen species were the pyridinic and amino nitrogen species. At high temperatures (650 and $850{ }^{\circ} \mathrm{C}$ ), the graphitic and $\mathrm{N}^{+}-\mathrm{O}^{-}$nitrogen species dominates.

The trend of changing nitrogen species with temperature is shown in Fig. 5 to show the influence of annealing temperature. For the nitrogen species of the aqueous ammonia treated samples, the pyridinic, amino, and pyrrollic nitrogen species first increased with temperature and then decreased. In contrast, the graphitic and $\mathrm{N}^{+}-\mathrm{O}^{-}$nitrogen species only increased with temperature. The different behavior of these nitrogen species with temperature resulted from their distinct chemical natures [27]. For example, the amino nitrogen species are only attached to the graphene sheets by a single $\mathrm{C}-\mathrm{N}$ bond, which is a result of the oxygen groups being reduced by ammonia. In contrary, the breaking of three $\mathrm{C}-\mathrm{C}$ bond and formation of $\mathrm{C}-\mathrm{N}$ bonds are needed to form the graphitic nitrogen. Clearly, a higher temperature is needed to accomplish this doping reaction. Moreo-

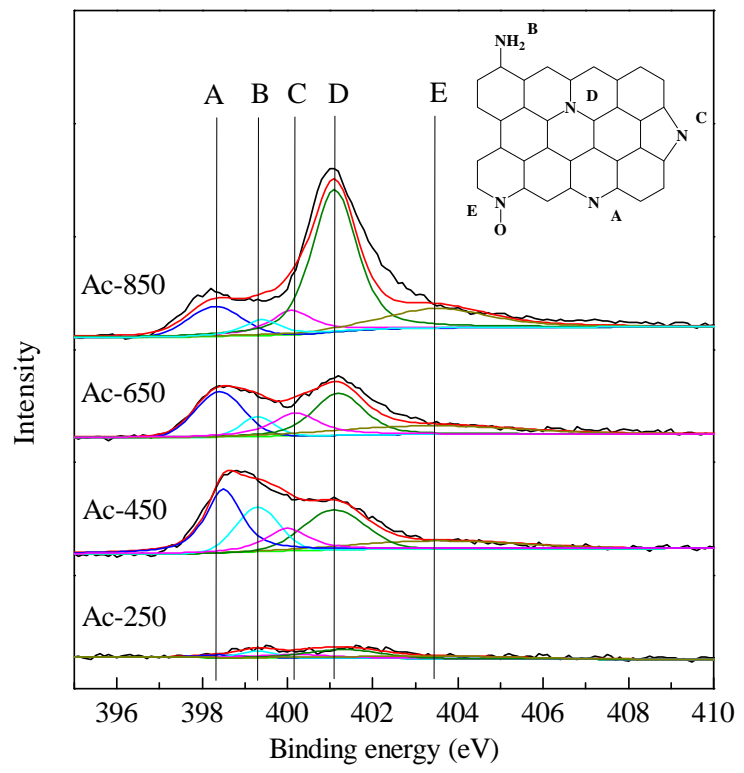

ver, amino nitrogen species are not stable at high temperatures since only an unstable single $\mathrm{C}-\mathrm{N}$ bond attached them to the graphene sheets. The nitrogen species with low binding energies (pyridinic amino and pyrrollic nitrogen) in the XPS spectra are easily formed and at the same time, easily broken off at high temperatures. However, the formation of graphitic and $\mathrm{N}^{+-} \mathrm{O}^{-}$ species needs high temperatures to overcome the high activation energy. The higher binding energies of the graphitic and $\mathrm{N}^{+-} \mathrm{O}^{-}$nitrogen species than the other nitrogen species is strong support for our deduction. The $\mathrm{N}$-doped samples prepared from acetonitrile and PGO followed the same trend because of the same chemical nature of the different nitrogen species. Our deduction also explained the phenomenon that Ac-650 has less nitrogen than the Ac- 450 sample. At $650{ }^{\circ} \mathrm{C}$, the amino nitrogen species decreased a lot and the other nitrogen species did not increase significantly. The different chemical nature of the different nitrogen species led to a best temperature to dope nitrogen atoms into the graphene sheets [26,27]. In contrast, the aqueous ammonia treatment process oxidized carbon atoms at high temperatures to provide more oxygen groups to be reduced by ammonia. Therefore, the $\mathrm{N}$ content of the aqueous ammonia treated samples did not show a volcano shape variation with temperature, but only an increase.

\subsection{Catalytic activity of $\mathrm{N}$-doped graphene in the selective oxidation of ethylbenzene}

The oxidation of ethylbenzene was chosen as the probe reaction to test the catalytic activity of these N-graphene materials. All the reactions gave acetophenone as the main products and some other oxidation products like benzaldehyde and benzoic acid as side products. Generally, the N-doped graphene materials treated at high temperatures exhibited better catalytic activity than those of those treated at low temperatures. However, Am-850 had a lower catalytic activity than the other materials. As we have demonstrated in a previous paper that

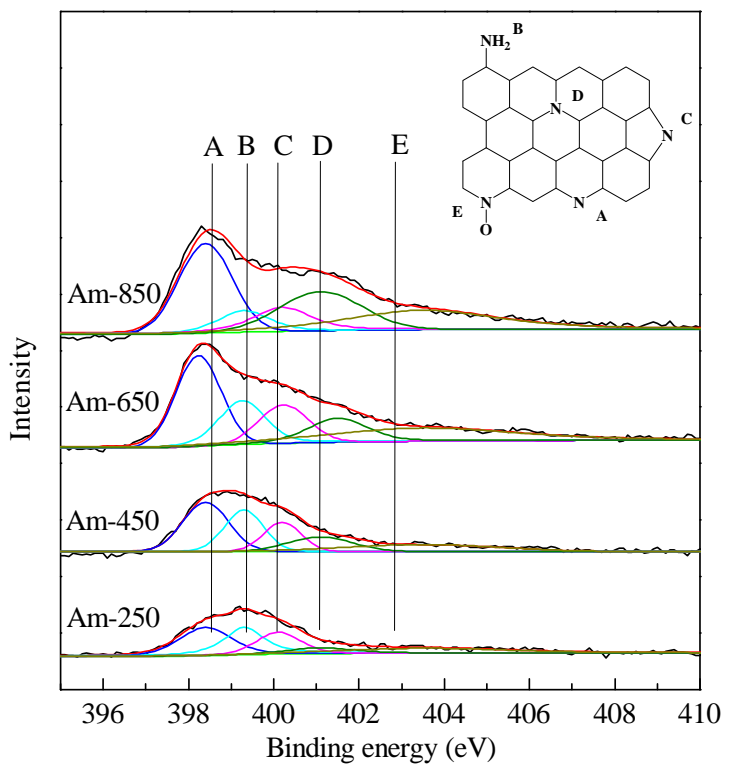

Fig. 4. N $1 s$ XPS spectra of the N-doped graphene materials. 


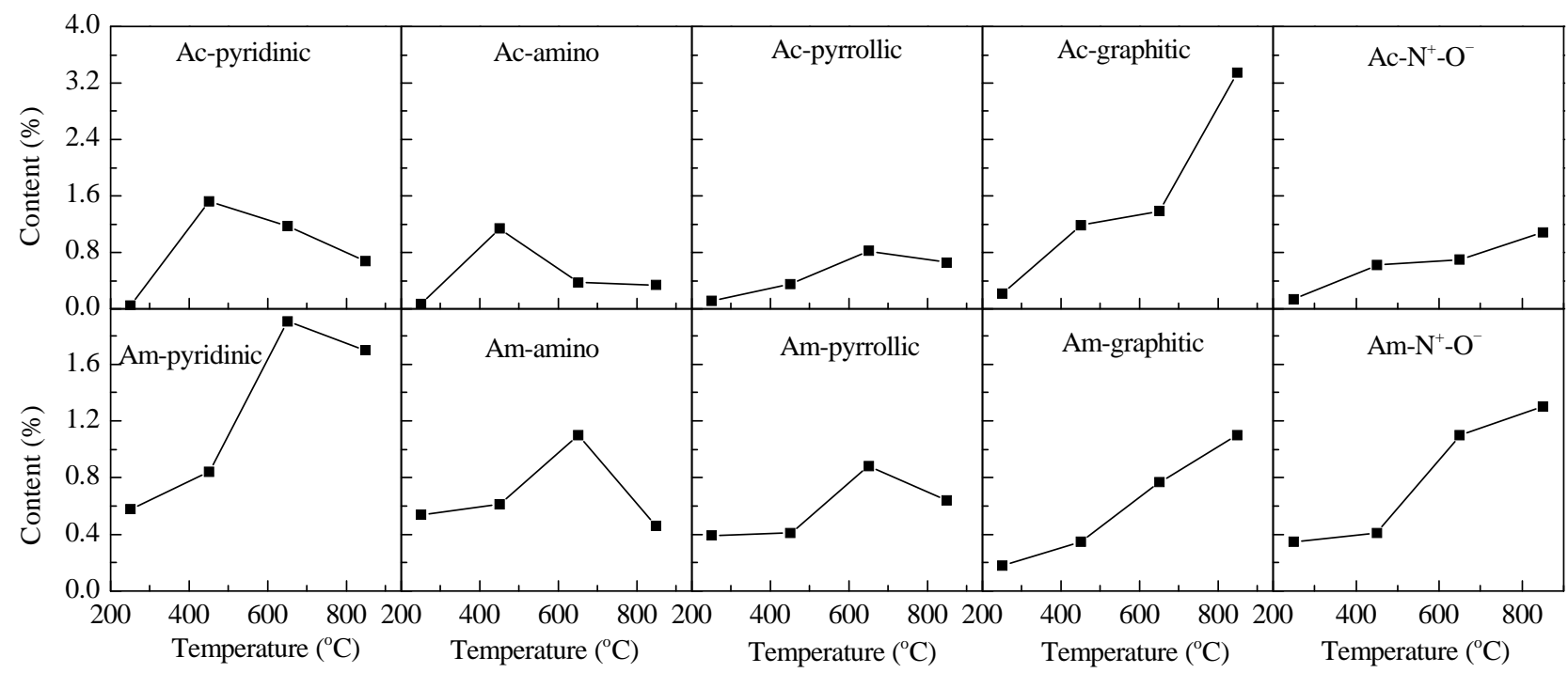

Fig. 5. Content of different $\mathrm{N}$ species as a function of annealing temperatures for the $\mathrm{N}$-doped graphene materials.

the graphitic nitrogen is responsible for the activation of TBHP [15], here we also correlated the contents of total nitrogen and graphitic nitrogen species with the yields of acetophenone in Table 3.

From Table 3 we can see that it is not total nitrogen but only the graphitic nitrogen species that are active in this catalytic reaction. First, for the instance of Ac-450 and Ac-650, the Ac-650 sample has a total nitrogen content of $3.8 \%$ which is lower than the content of Ac- 450 at $4.8 \%$. Nevertheless, the similarity of the contents of graphitic nitrogen species $(1.5 \%$ and $1.7 \%$ ) causes them to show similar yields of acetophenone. However, it is of note that the Am-850 sample which has the most abundant defects and the second highest graphitic nitrogen species content was less active than all the other materials. We proposed that this sample was too active to promote the decomposition of TBHP because too much oxidant was wasted.

Table 3

Catalytic activity of $\mathrm{N}$-doped graphene materials in the selective oxidation of ethylbenzene.

\begin{tabular}{lccccc} 
Entry & Sample & $\begin{array}{c}\text { Yield of } \\
\text { acetophenone } \\
(\%)\end{array}$ & $\begin{array}{c}\text { Nitrogen } \\
\text { element } \\
(\%)\end{array}$ & $\begin{array}{c}\text { Oxygen } \\
\text { element } \\
(\%)\end{array}$ & $\begin{array}{c}\text { Graphitic } \\
\text { nitrogen } \\
(\%)\end{array}$ \\
\hline 1 & Ac-250 & 55.9 & 0.59 & 11 & 0.21 \\
2 & Ac-450 & 84.1 & 4.8 & 7.9 & 1.2 \\
3 & Ac-650 & 87.9 & 3.8 & 4.0 & 1.4 \\
4 & Ac-850 & 81.6 & 6.1 & 3.0 & 3.4 \\
$5^{*}$ & Ac-850 & 49.9 & 6.1 & 3.0 & 3.4 \\
6 & Am-250 & 55.8 & 2.0 & 9.5 & 0.18 \\
7 & Am-450 & 86.5 & 2.6 & 7.9 & 0.35 \\
8 & Am-650 & 93.2 & 4.6 & 3.9 & 0.77 \\
9 & Am-850 & 57.9 & 5.2 & 4.6 & 1.1 \\
$10^{*}$ & Am-850 & 81.9 & 5.2 & 4.6 & 1.1 \\
\hline
\end{tabular}

Reaction conditions: 1 mmol ethylbenzene, $3 \mathrm{mmol}$ TBHP, 10 mg catalyst and $3 \mathrm{~mL} \mathrm{H}_{2} \mathrm{O}$ were put into a $50 \mathrm{~mL}$ sealed pressure glass vessel with magnetic stirring, $80^{\circ} \mathrm{C}\left(* 65^{\circ} \mathrm{C}\right), 24 \mathrm{~h}$.
This is shown by the TBHP decomposition curves shown in Fig. 6 where Ac-850 showed a significantly faster decomposition rate of TBHP than that of any other samples. The most active Ac-650 showed a high and modest decomposition rate. Our similar observation that the kinetic control of the decomposition of $\mathrm{H}_{2} \mathrm{O}_{2}$ was essential in the benzene oxidation reaction is strong support to our proposal in this paper [22]. Second, the ability of the two precursors in activating the PGO materials was also compared. Obviously, Ac-650 prepared from aqueous ammonia showed a higher yield than the other catalysts. In order to further compare the activities of these N-doped graphene materials, we also used the Ac-850 and Am-850 samples to catalyze this reaction at a lower temperature $\left(65^{\circ} \mathrm{C}\right)$. Compared with the reactions at $80{ }^{\circ} \mathrm{C}, \mathrm{Am}-850$ showed a better catalytic activity, while the Ac- 850 sample was less active. This phenomenon agreed with Fig. 6 that Am-850 was much more active than the Ac-850 sample in catalyzing the decomposition of TBHP. Therefore at a lower temperature, Am-850 would show a better catalytic activity due to its better TBHP decom-

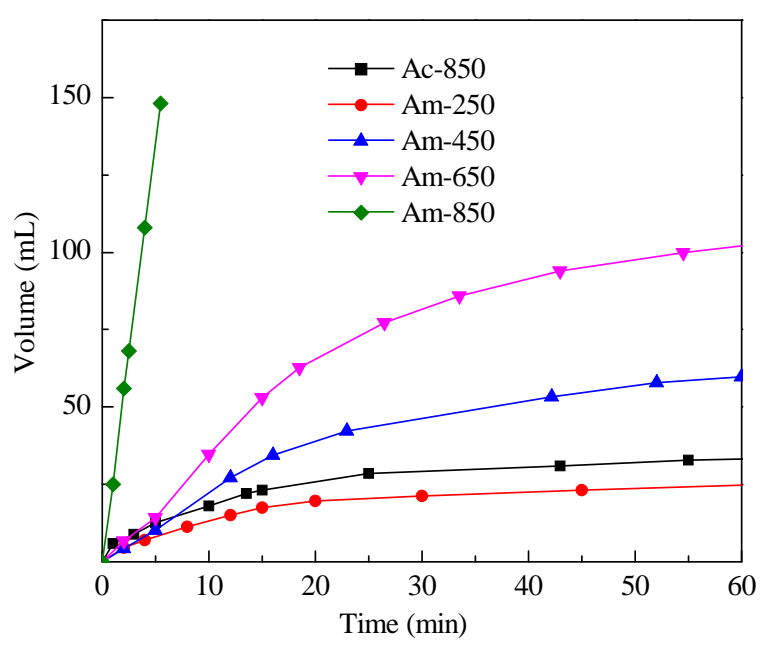

Fig. 6. TBHP decomposition by the N-doped graphene materials. 
position ability. Therefore, aqueous ammonia is a more effective doping precursor than acetonitrile in activating carbon materials in this ethylbenzene oxidation reaction.

\section{Conclusions}

The growth mechanism of $\mathrm{N}$ species in $\mathrm{N}$-doped graphene materials and their corresponding catalytic activity in the selective oxidation of ethylbenzene were investigated. The nitrogen content and compositions of the nitrogen species can be changed by the nitrogen precursor used and annealing temperature. The nitrogen species at low and high binding energies showed different trends with temperatures and these differences were due to their chemical nature. These $\mathrm{N}$-doped graphene are good catalysts in the selective oxidation of ethylbenzene. In this reaction, it is not the total nitrogen elements but only the graphitic nitrogen species that are responsible for the reaction to acetophenone. A modest oxidant decomposition rate is important in achieving a high yield of acetophenone. Too much graphitic nitrogen species and defects have a negative role. This paper will help understand the growth mechanism of dopants in graphene materials and help prepare more active carbocatalysts.

\section{References}

[1] Rodriguez-Reinoso F. Carbon, 1998, 36: 159

[2] Serp P, Corrias M, Kalck P. Appl Catal A, 2003, 253: 337

[3] Huang C C, Li C, Shi G Q. Energy Environ Sci, 2012, 5: 8848

[4] Machado B F, Serp P. Catal Sci Technol, 2012, 2: 54

[5] Su C L, Loh K P. Acc Chem Res, 2013, 46: 2275

[6] Su D S, Perathoner S, Centi G. Chem Rev, 2013, 113: 5782

[7] Dreyer D R, Bielawski C W. Chem Sci, 2011, 2: 1233

[8] Su D S, Zhang J, Frank B, Thomas A, Wang X C, Paraknowitsch J, Schlögl R. ChemSusChem, 2010, 3: 169
[9] Mestl G, Maksimova N I, Keller N, Roddatis V V, Schlögl R. Angew Chem Int Ed, 2001, 40: 2066

[10] Liu X, Frank B, Zhang W, Cooter P T, Schlögl R, Su D S. Angew Chem Int Ed, 2011, 50: 3318

[11] Yu H, Peng F, Tan J, Hu X W, Wang H J, Yang J, Zheng W X. Angew Chem Int Ed, 2011, 50: 3978

[12] Long J L, Xie X Q, Xu J, Gu Q, Chen L M, Wang X X. Acs Catal, 2012, 2: 622

[13] Gao Y J, Ma D, Wang C L, Guan J, Bao X H. Chem Commun, 2011, 47: 2432

[14] Liu C, Tang P, Chen A B, Hu Y Q, Yu Y F, Lü H J, Ma D. Mater Lett, 2013, 108: 285

[15] Gao Y J, Hu G, Zhong J, Shi Z J, Zhu Y S, Su D S, Wang J G, Bao X H, Ma D. Angew Chem Int Ed, 2013, 52: 2109

[16] Yang J H, Sun G, Gao Y J, Zhao H B, Tang P, Tan J, Lu A H, Ma D. Energy Environ Sci, 2013, 6: 793

[17] Zhang J, Liu X, Blume R, Zhang A H, Schlogl R, Su D S. Science, 2008, 322: 73

[18] Kong X K, Sun Z Y, Chen M, Chen C L, Chen Q W. Energy Environ Sci, 2013, 6: 3260

[19] Sheng Z H, Gao H L, Bao W J, Wang F B, Xia X H. J Mater Chem, 2012, 22: 390

[20] Kong X K, Chen C L, Chen Q W. Chem Soc Rev, 2014, 43: 2841

[21] Larsen J W, Freund M, Kim K Y, Sidovar M, Stuart J L. Carbon, 2000, 38: 655

[22] Yang J H, Sun G, Gao Y J, Zhao H B, Tang P, Tan J, Lu A H, Ma D. Energy Environ Sci, 2013, 6: 793

[23] Martins Ferreira E H, Moutinho M V O, Stavale F, Lucchese M M, Capaz R B, Achete C A, Jorio A. Phys Rev B, 2010, 82: 125429/1

[24] Li X L, Wang H L, Robinson J T, Sanchez H, Diankov G, Dai H J. J Am Chem Soc, 2009, 131: 15939

[25] Zhao H B, Zhu Q J, Gao Y J, Zhai P, Ma D. Appl Catal A, 2013, 456: 233

[26] Lai L F, Potts J R, Zhan D, Wang L, Poh C K, Tang C H, Gong H, Shen Z X, Jianyi L Y, Ruoff R S. Energy Environ Sci, 2012, 5: 7936

[27] Zhang L S, Liang X Q, Song W G, Wu Z Y. Phys Chem Chem Phys, 2010, 12: 12055

\section{Graphical Abstract}

Chin. J. Catal., 2013, 34: 922-928 doi: 10.1016/S1872-2067(14)60150-9

Growth mechanism of $\mathrm{N}$-doped graphene materials and their catalytic behavior in the selective oxidation of ethylbenzene

Pei Tang, Yongjun Gao, Jinghe Yang, Wenjing Li, Huabo Zhao, Ding Ma*

Peking University
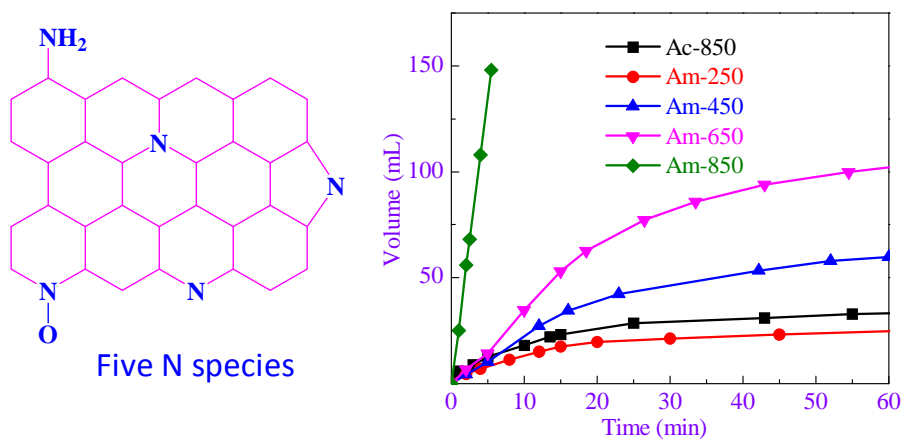

Growth mechanisms of N-doped graphene materials, which are good catalysts in the selective oxidation of ethylbenzene, were investigated. The kinetic control of the decomposition of the oxidants is important in this reaction. 


\title{
氮掺杂石墨烯的生长机理及其在乙苯选择性氧化中的应用
}

\author{
唐 沛，高勇军，杨敬贺，李文静，赵华博，马 $丁^{*}$ \\ 北京大学化学与分子工程学院 北京100871
}

摘要: 以热解氧化石墨烯材料为碳基底, 分别使用有机氮源和无机氮源对其进行氮掺杂处理, 制备了一系列氮掺杂石墨烯材料. 采用透射电子显微镜、扫描电子显微镜、拉曼光谱和X射线光电子能谱等表征方法考察了氮掺杂石墨烯的生长机理. 结果表明, 随 着制备过程中退火温度的改变,氮掺杂石墨烯中不同氮物种的含量有显著差别. 这种差异是由不同氮物种化学环境的差异所导 致的. 所制备的含氮石墨烯材料对乙苯选择性氧化制苯乙酮反应均表现出优良的催化活性. 其中, 石墨氮的含量对于提高苯乙酮 收率起到至关重要的作用. 此外, 通过氧化剂控制活化的方法可以消除过多的结构缺陷和过量氮掺杂对催化反应的不利影响, 有 效提升氮掺杂石墨烯的催化活性.

关键词: 氮掺杂石墨烯; 杂原子; 生长机理; 乙苯氧化反应

收稿日期: 2014-05-15. 接受日期: 2014-05-21. 出版日期: 2014-06-20.

*通讯联系人. 电话: (010)62758603; 传真: (010)62758603; 电子信箱: dma@pku.edu.cn

基金来源：国家自然科学基金(21176221, 21273224); 国家重点基础研究发展计划(973计划, 2011CB201402, 2013CB933100).

本文的英文电子版由Elsevier出版社在ScienceDirect上出版(http://www.sciencedirect.com/science/journal/18722067). 